\title{
Rapid change in mouse mitochondrial DNA
}

\section{Wild mice around Chicago may have switched genotype to keep pace with modern living.}

W e have compared the sequences of mitochondrial DNA extracted from museum skins of white-footed mice caught in the Chicago area since 1855 and from modern mice trapped alive in the same locations. We found a consistently similar directional change of mouse genotype over this period at each of five collection sites that were separated by $10-70 \mathrm{~km}$. The genotype most common 100 years ago is now extremely rare, indicating that the mammalian mitochondrial genome can undergo rapid evolution.

Museums from Alaska to Switzerland were searched for specimens of the whitefooted mouse, Peromyscus leucopus, originally collected from two counties in northeastern Illinois, USA. The white-footed mouse is the most common rodent in the deciduous forests of North America. We borrowed 61 museum-specimen skins of mice collected from five locations in the Chicago area, and in 1999 we trapped 52 white-footed mice in the same locations and in three others.

Small $(12 \mathrm{~mm} \times 1.5 \mathrm{~mm})$ strips were cut from the ventral suture of the museumspecimen mouse skins. We found that shaving the hair from these strips before extraction, combined with a freeze-thaw step, reduced the dark colour of the extract and prevented inhibition of the polymerase chain reaction $(\mathrm{PCR})^{1}$. The Chelex-100 DNA-extraction protocol ${ }^{2}$ was modified by the addition of proteinase $\mathrm{K}$ (ref. 3 ).

We used a 340-base-pair polymorphic region within the coding portion of the cytochrome oxidase II gene to genotype the museum mouse skins. This region was amplified for sequencing of DNA from 56 of 61 skins by using KlentaqLA DNA polymerase and PCR buffer (DNA Polymerase Technology) ${ }^{4-7}$, extremely long $(20-\mathrm{min})$ extension cycles ${ }^{5}$ and betaine ${ }^{8}$, in conjunction with three nested PCR primer sets spanning 559, 496 and 400 base pairs in turn.

Three haplotypes (named $A, M$ and $M w$ ) were identified: $M w$ was found in only three mice. $M$ and $M w$ differ at just a single position, but they both differ from $A$ at four positions in this 340-base-pair region (see supplementary information); none of the base changes alters the amino-acid sequence of the gene.

At four of the five collection sites, the oldest white-footed mice were predominantly of genotype $A$. At each geographical location there was a monotonic decrease in the proportion of $A$ (Fig. 1). Pooling sequencing data for all five locations, the proportion of $A$ was 5/5 in 1850-99, 18/30

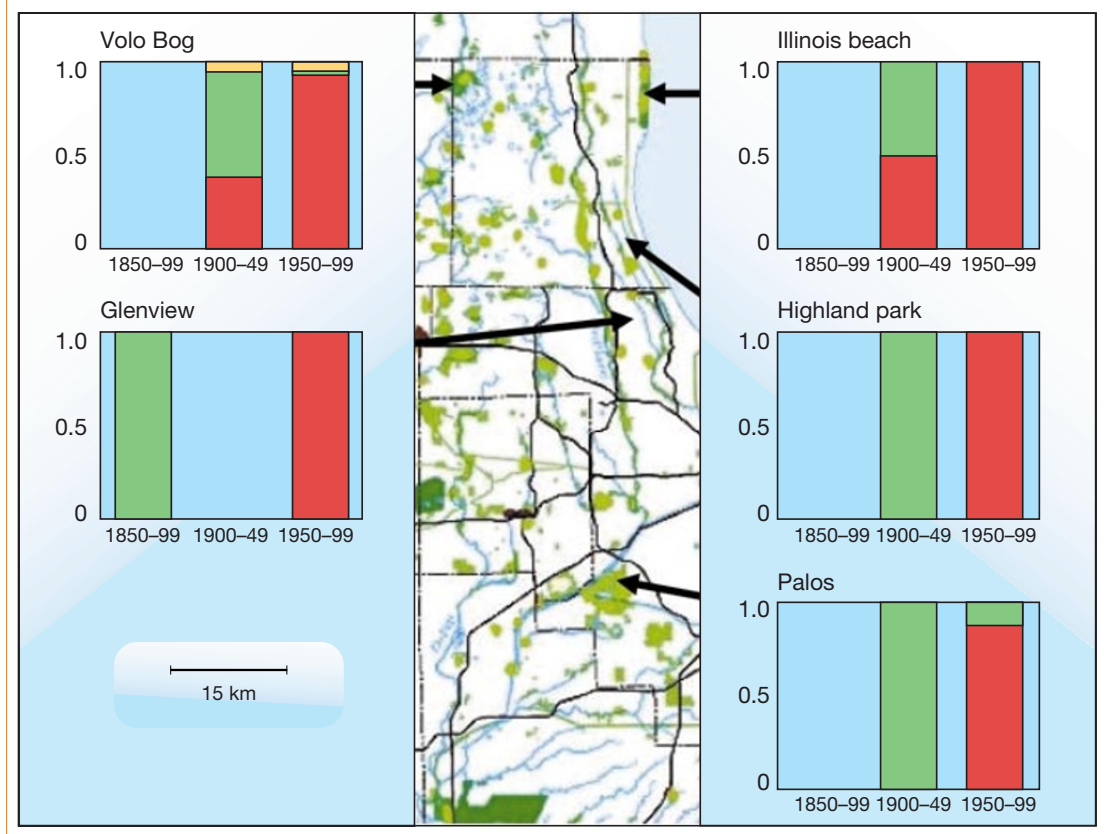

Figure 1 Modern map of the Chicago region where the change in genetic diversity of white-footed mice over 150 years was analysed. The geographic relation is shown between the five locations (arrows) from which pre-1950 museum specimens of Peromyscus leucopus were obtained. Major highways are shown in black; natural areas are shown in green. The frequencies (vertical scale) of three different mitochondrial haplotypes ( $A$, green; $M$, red; $M w$, yellow) are shown for each location for the periods 1850-99, 1900-49 and 1950-2000

in 1900-49 and $4 / 73$ in 1950-99. The observed frequency change requires less than a $1 \%$ per generation advantage of $M$ over $A$. None of the live mice trapped at these five locations had the $A$ type, and only one A mouse was trapped in 1999-2000.

As the change in the mitochondrial genotype of the wild mouse coincides with a marked increase in human activity in the region, we presume that this caused the replacement of the $A$ haplotype by the $M$. The $M$ genotype might have become advantageous in the altered habitat, or it could be unconditionally advantageous and have been introduced by people from elsewhere.

In the Chicago region, the white-footed mouse (Fig. 2) has displaced the prairie deer mouse from the few remaining

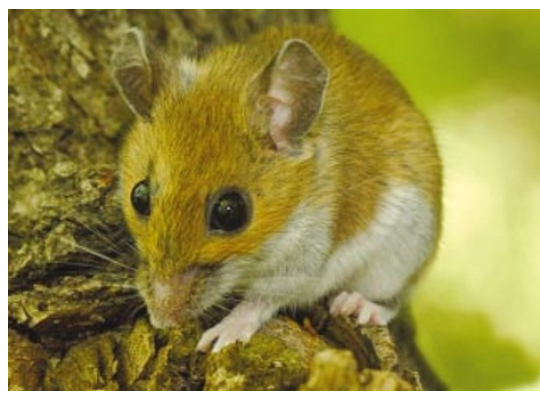

Figure 2 The white-footed mouse, originally a forest-dweller. prairies $^{9,10}$. We suggest that the $M$ haplotype has not only spread through the whitefooted mouse population but might also have contributed to the displacement of the prairie deer mouse by the whitefooted mouse.

Oliver R.W. Pergams ${ }^{\star} \dagger$, Wayne M. Barnes $\ddagger$, Dennis Nyberg*

*Department of Biological Sciences, University of Illinois at Chicago, Chicago, Illinois 60607, USA

$\dagger$ Present address: Department of Conservation Biology, Chicago Zoological Society and Smith Fellows Program, The Nature Conservancy,

Brookfield, Illinois 60513, USA

e-mail:olpergam@brookfieldzoo.org

$\$$ Department of Biochemistry and Molecular

Biophysics, Washington University in St Louis School of Medicine, St Louis, Missouri 63110, USA

1. Goodyear, P. D., MacLaughlin-Black, S. \& Mason, I. J. Biotechniques 16, 232-233 (1994).

2. Walsh, P. S., Metzger, D. A. \& Higuchi, R. Biotechniques 10, 506-513 (1991).

3. Steinberg, E. K. Mol. Ecol. 8, 1075-1092 (1999).

4. Barnes, W. M. Gene 112, 29-35 (1992).

5. Barnes, W. M. Trends Biochem. Sci. 19, 342 (1994).

6. Barnes, W. M. Proc. Natl Acad. Sci. USA 91, 2216-2220 (1994).

7. Barnes, W. M. US Patent No. 5,436,149 (1995).

8. Baskaran, N. et al. Genome Res. 6, 633-638 (1996).

9. Pergams, O. R. W. \& Nyberg, D. J. Mammalogy 82, 984-992 (2001).

10. Pergams, O. R. W. \& Nyberg, D. Proc. R. Soc. Lond. B (submitted). Supplementary information accompanies this communication on Nature's website.

Competing financial interests: declared (see online version). 
2nd edn (Appleton, New York, 1872/1897).

4. Hinde, R. A. \& Rowell, T. E. Proc. Zool. Soc. Lond. 138, 1-21 (1962)

5. Rowell, T. E. \& Hinde, R. A. Proc. Zool. Soc. Lond. 138, 279-294 (1962)

6. Hauser, M. D., Evans, C. S. \& Marler, P. Anim. Behav. 45, 423-433 (1993).

\section{Biomechanics}

\section{Bacterial flagellar switching under load}

lagellated bacteria swim up gradients of - chemical attractants by modulating the direction of rotation of their flagellar motors, but how this switching mechanism works is not understood. Here we show that the probability of the motor rotating in the clockwise direction increases under high load, when the motor spins slowly (at less than $50 \mathrm{~Hz}$ ). We suggest that either the switch is responding to small changes in torque the torque increases only fractionally between $50 \mathrm{~Hz}$ and stall - or it senses motor speed, perhaps by means of proton flux.
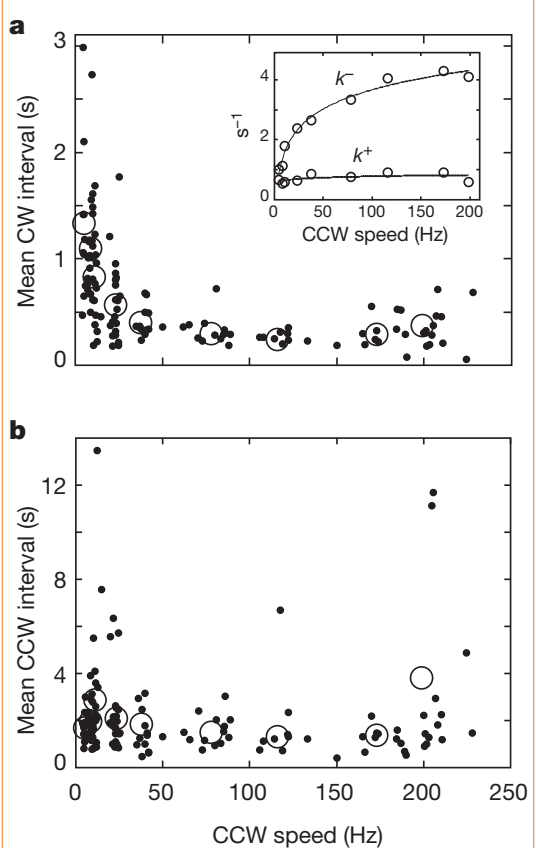

Figure 1 Behaviour of the flagellar switch of Escherichia coli under different loadings. a, b, Mean intervals for clockwise (CW; $\mathbf{a}$ ) and counterclockwise (CCW; b) rotation of the flagellar motor, plotted as a function of mean CCW speed. Filled symbols, values measured for each cell; hollow symbols, averages over the ensemble of cells for beads of a given size, with the values for each cell being weighted equally. Bead diameters were $0.36,0.54,0.74$, $1.03,1.20,1.44,1.79,2.13$ and $2.60 \mu \mathrm{m}$ (from right to left); the number of cells studied for each of these bead sizes was 12, 12, $7,12,12,18,18,16$ and 10, respectively. Each bead was monitored for 5 min at $20^{\circ} \mathrm{C}$. Inset, rate constants $k^{-}=1 /$ (mean CW interval) and $k^{+}=1 /$ (mean CCW interval) were computed for each cell and then averaged over the ensemble of cells for beads of a given size, with the values for each cell being weighted equally.
7. Partan, S. R. Behaviour 139, 993-1027 (2002).

8. Kuhl, P. K. \& Meltzoff, A. N. Science 218, 1138-1141 (1982).

9. Patterson, M. L. \& Werker, J. F. Inf. Behav. Dev. 22, 237-247 (1999).

10. Geschwind, N. Brain 88, 237-294 (1965).

11. Liberman, A. M. \& Mattingly, I. G. Cognition 21, 1-36 (1985).

Competing financial interests: declared none.

Flagellar filaments of an Escherichia coli sticky-filament mutant ${ }^{1}$, which is otherwise wild-type for chemotaxis, were shortened by viscous shear, and cell bodies were fixed to a polylysine-coated glass coverslip. Latex beads of various sizes were adsorbed to filament stubs and their rotation was followed in a weak optical trap with a quadrant detector ${ }^{2}$

Figure 1 shows clockwise and counterclockwise intervals for rotation plotted as a function of counterclockwise speed, together with rate constants for transitions between the clockwise and counterclockwise states. Clockwise intervals lengthened appreciably at high loading ( $k^{-}$decreased), whereas counterclockwise intervals remained about the same for all loads $\left(k^{+}\right.$remained roughly constant).

A similar asymmetrical performance is seen under the action of fumarate ${ }^{3}$. However, when an attractant is added, the cells respond by shortening their clockwise intervals and lengthening their counterclockwise intervals ${ }^{4}$. From the results shown in Fig. 1, it follows that a motor that is spinning rapidly, as motors do in swimming cells, will spend a larger fraction of its time turning counterclockwise and will change direction more frequently than a motor that is spinning slowly, as motors do in tethered cells.

In a wild-type cell, the direction in which the motor spins depends on the degree of phosphorylation of a small signalling protein, CheY, which is activated by a kinase that is coupled to the chemoreceptors ${ }^{5}$. To determine whether this signalling pathway is involved in the load response, we repeated a number of measurements using cells in which this pathway had been disrupted. We used a strain in which cheY, cheA (which encodes the kinase) and che $Z$ (which encodes a phosphatase) were all deleted and which expressed CheY ${ }^{13 \mathrm{DK} 106 \mathrm{YW}}\left(\mathrm{CheY}^{* *}\right)$, a variant with fixed activity ${ }^{1}$. The response to different loadings was the same as that of wild-type cells, indicating that the motor's sensitivity to load is probably not due to feedback from the chemotaxis signalling network, but is instead an inherent property of the motor.

The bacterial flagellar motor is powered by protons moving down an electrochemical gradient and has a distinctive torque-speed relationship. At $20{ }^{\circ} \mathrm{C}$, the relative torque falls gradually from unity at stall to about 0.9 at $120 \mathrm{~Hz}$, and drops rapidly to zero at about $260 \mathrm{~Hz}$ (ref. 6); in the latter regime, the torque decreases markedly at lower temperatures or when $\mathrm{H}_{2} \mathrm{O}$ is replaced by $\mathrm{D}_{2} \mathrm{O}$ (ref. 7), indicating that the movement of mechanical parts and/or of protons becomes rate limiting.

We found switching to be particularly sensitive to load only during high-torque, low-speed operation, and mainly at speeds of less than about $50 \mathrm{~Hz}$ (Fig. 1). Over this speed range, the torque changes by about $5 \%$. There is evidence that each revolution of the motor requires the passage of a fixed number of protons ${ }^{8}$. So, rather than sensing changes in torque, might the switch be monitoring proton flux?

Flagellated bacteria are sensitive to a variety of environmental factors, including mechanical stimuli. Swimming in viscous solutions or near surfaces can trigger developmental changes - for example, swarmer-cell differentiation in $E$. coli ${ }^{9}$ or lateral flagellar synthesis in the marine organism Vibrio ${ }^{10}$. In the latter case, changes in gene expression occur in response to exposure to sodium-channel blockers, indicating that they might be caused by a reduction in motor ion flux ${ }^{11}$. It is possible that these different responses rely on a common mechanosensory mechanism.

Karen A. Fahrner, William S. Ryu,

Howard C. Berg

Department of Molecular and Cellular Biology, Harvard University, Cambridge, Massachusetts 02138, USA, and Rowland Institute at Harvard, Cambridge, Massachusetts 02142, USA

e-mail:hberg@biosun.harvard.edu

1. Scharf, B. E., Fahrner, K. A., Turner, L. \& Berg, H. C. Proc. Natl Acad. Sci. USA 95, 201-206 (1998).

2. Ryu, W. S., Berry, R. M. \& Berg, H. C. Nature 403, 444-447 (2000).

3. Prasad, K., Caplan, S. R. \& Eisenbach, M. J. Mol. Biol. 280 , 821-828 (1998).

4. Block, S. M., Segall, J. E. \& Berg, H. C. J. Bacteriol. 154, 312-323 (1983).

5. Bourret, R. B. \& Stock, A. M. J. Biol. Chem. 277, 9625-9628 (2002)

6. Chen, X. \& Berg, H. C. Biophys. J. 78, 1036-1041 (2000).

7. Chen, X. \& Berg, H. C. Biophys. J. 78, 2280-2284 (2000).

8. Meister, M., Lowe, G. \& Berg, H. C. Cell 49, 643-650 (1987)

9. Harshey, R. M. Mol. Microbiol. 13, 389-394 (1994).

10. McCarter, L. L. Microbiol. Mol. Biol. Rev. 65, 445-462 (2001).

11. Kawagishi, I., Imagawa, M., Imae, Y., McCarter, L. \& Homma, M. Mol. Microbiol. 20, 693-699 (1996).

Competing financial interests: declared none.

\section{erratum}

Rapid change in mouse mitochondrial DNA

Oliver R. W. Pergams, Wayne M. Barnes, Dennis Nyberg Nature 423, 397 (2003)

There is an error in the Volo Bog and Glenview components of Fig. 1 of this communication: two $\mathrm{Mw}$ haplotype mice were shown in the 1950-99 column of the former that should have been in the 1950-99 column of the latter. This mistake does not affect the conclusions, as the analysis was done with mice from the correct category. Sample sizes (left and right columns, respectively) for the different locations were Volo Bog, 19 and 41; Glenview, 5 and 6; Illinois Beach, 8 and 5; Highland Park, 2 and 5; Palos, 1 and 8 (note that sample numbers were inevitably low for museum specimens). 